\title{
Evaluasi Penggunaan Antibiotik pada Pasien Bedah Caesar dan Hernia di Salah Satu Rumah Sakit di Jawa Barat
}

\author{
Nisa Maulani Nuraliyah", Zelika Mega Ramadhania, Eni Syofiah \\ Program Studi Sarjana Farmasi, Fakultas Farmasi, Universitas Padjadjaran \\ *email: nisamaulani29@gmail.com \\ (Submit 20/8/2019, Revisi 21/8/2019, Diterima 25/8/2019)
}

\begin{abstract}
Abstrak
Antimikroba mempunyai peranan besar dalam penanganan penyakit infeksi, namun adanya penggunaan yang tidak tepat dan berlebihan memicu terjadinya resistensi. Salah satu yang paling umum adalah resistensi terhadap antibiotik. Di rumah sakit, antibiotik banyak digunakan untuk penanganan penyakit infeksi maupun pada prosedur bedah sebagai profilaksis. Merujuk pada Peraturan Menteri Kesehatan Nomor 8 tahun 2015 tentang Program Pengendalian Resistensi Antimikroba dan bahwa penggunaan antibiotik di rumah sakit harus dikendalikan, salah satu bentuk pengendalian adalah melalui evaluasi penggunaan antibiotik. Tujuan dari penelitian ini adalah mendapatkan gambaran penggunaan antibiotik pada pasien bedah Caesar dan hernia di salah satu rumah sakit di Jawa Barat periode September - November 2018. Evaluasi penggunaan antibiotik dilakukan dengan metode penilaian Defined Daily Dose (DDD)/100 hari rawat. Hasil evaluasi menunjukan antibiotik yang paling banyak digunakan adalah ceftriaxone dengan nilai $32.95 \mathrm{DDD} / 100$ hari rawat pada bedah hernia dan 62.58 DDD/100 hari rawat untuk bedah caesar.
\end{abstract}

Kata kunci: antibiotik, ATC/DDD, evaluasi

\section{Outline}

- Pendahuluan

- Metode

- Hasil dan Pembahasan

- Kesimpulan

- Daftar Pustaka

\section{Pendahuluan}

Antimikroba merujuk pada sekelompok obat yang digunakan untuk menangani infeksi mikroorganisme pada tubuh (Nankervis H, Thomas KS, Delamare FM et al, 2016). Peran antimikroba begitu besar dalam penanganan penyakit infeksi yang secara nyata menurunkan angka kematian dan keparahan penyakit karena infeksi mikroorganisme. Di sisi lain, mikroorganisme perlahan mengalami resistensi terhadap antimikroba sehingga menurunkan efektivitasnya dalam membunuh agen penginfeksi. Hal ini terutama terjadi pada antibiotik. 
Resistensi antibiotik berkembang sejak antibiotik mula-mula digunakan. Pada kasus penisilin, yang ditemukan pada tahun 1928 dan diresepkan pertama kali pada tahun 1940-an, mulai berkembang resistensi terhadap penisilin sekitar tahun 1950-an (Spellberg and Gilbert, 2014). Menurut Central Disease Center (CDC) Amerika Serikat menyebutkan bahwa resistensi sudah terjadi hampir pada semua antibiotik yang telah dikembangkan (CDC, 2013). Beberapa hal yang menyebabkan resistensi antibiotik antara lain penggunaan berlebihan, penggunaan tidak tepat, banyaknya penggunaan di bidang pertanian, minimnya penemuan antibiotik baru, dan hambatan-hambaan regulasi (Ventola, 2015).

Rumah sakit merupakan tempat antibiotik digunakan secara luas untuk menangani infeksi dengan berbagai diagnosis. Central Disease Control (CDC) Amerika Serikat menyebutkan lebih dari separuh pasien rumah sakit menerima antibiotik selama perawatan di rumah sakit namun penggunaan yang tinggi ini berkaitan dengan terjadinya resistensi antibiotik (CDC, 2017; Cusini et al., 2018). Melihat adanya tren ini, di Indonesia setiap rumah sakit harus melakukan pengendalian resistensi antimikroba sebagaimana diatur dalam PMK No. 8 tahun 2015 dan diamanatkan sebagai Program Nasional dalam SNARS Edisi I (Standar Nasional Akreditasi Rumah Sakit).

Salah satu bentuk pengendalian resistensi antibiotik berdasarkan PMK No. 8 tahun 2015 dapat dilakukan melalui evaluasi penggunaan obat antibiotik baik secara kuantitatif maupun kualitatif. Evaluasi penggunaan antibiotik secara kuantiitatif dilakukan menggunakan metode DDD (Defined Daily Dose) merupakan metode evaluasi penggunaan rata-rata harian antibiotik dibandingkan dengan defined dose yang ditetapkan oleh World Health Organization (WHO).

Prosedur bedah seringkali menyebabkan terjadinya infeksi, sehingga adakalanya antibiotik diberikan untuk mencegah infeksi bakteri pasca operasi/profilaksis (SIGN, 2014), maupun diberikan dengan indikasi terapi. Tulisan ini bertujuan untuk memberikan gambaran penggunaan antibiotik menggunakan metode ATC/DDD pada pasien departemen bedah dengan diagnosis bedah SC dan hernia periode bulan September - November 2018.

\section{Metode}

Data yang diambil merupakan data penggunaan antibiotik pada pasien bedah SC dan bedah hernia pada bulan September hingga November 2018 yang diambil melalui sistem informasi rumah sakit (HIS) yang bersifat online. Data dievaluasi kelengkapan dan kejelasan informasi dan dieksklusi beberapa data karena tidak memenuhi kriteria. Kriteria eksklusi yang ditetapkan antara lain 1) informasi lengkap; 2) data jelas. Data diolah menggunakan aplikas Microsoft Excel.

\section{Hasil dan Pembahasan}

Evaluasi penggunaan antibiotik secara kuantitatif telah dilakukan berdasarkan data pasien rawat inap bedah hernia dan SC periode September hingga November 2018. Sumber data adalah sistem informasi online rumah sakit. Kriteria eksklusi dari data awal antara lain kelengkapan data dan kejelasan data. Berikut gambaran deskriptif data sampel penelitian. 
Tabel 1. Gambaran sampel penelitian

\begin{tabular}{|c|c|c|}
\hline \multirow{2}{*}{ Gambaran Sampel } & SC & HILL \\
\hline & $n(\%)$ & $n(\%)$ \\
\hline Jumlah data pasien & $60(100)$ & $19(100)$ \\
\hline \multicolumn{3}{|l|}{ Lama rawat } \\
\hline 2 hari & 0 & $6(31.58)$ \\
\hline 3 hari & $24(40.00)$ & $4(21.05)$ \\
\hline 4 hari & $27(45.00)$ & $6(31.58)$ \\
\hline 5 hari & $3(5.00)$ & $2(10.53)$ \\
\hline 6 hari & $5(8.33)$ & 0 \\
\hline 7 hari & $1(1.67)$ & \\
\hline 8 hari & 0 & $1(5.26)$ \\
\hline \multicolumn{3}{|l|}{ Prosedur operasi } \\
\hline \multicolumn{3}{|l|}{ SC } \\
\hline SC & $42(70.00)$ & \\
\hline $\mathrm{SC}+\mathrm{MOW}$ & $5(8.33)$ & - \\
\hline SC + MOW + Adhesiolisis & $1(1.67)$ & \\
\hline SC+ B Lynch suture & 7 (11.67) & - \\
\hline SC + B Lynch suture + Insersi IUD & $1(1.67)$ & \\
\hline SC + Adhesiolisis & $1(1.67)$ & - \\
\hline SC + Insersi IUD & $1(1.67)$ & - \\
\hline SC + Sterilisasi pomeroy & $2(3.33)$ & \\
\hline \multicolumn{3}{|l|}{ Hernia } \\
\hline Hernioraphy & - & $1(5.26)$ \\
\hline Herniotomy & - & 6 (31.58) \\
\hline Hernioraphy + MESH & - & $10(52.63)$ \\
\hline Hernioraphy + Herniotomy + MESH & - & $1(5.26)$ \\
\hline $\begin{array}{l}\text { Hernioraphy + Herniotomy + Incidental } \\
\text { appendectomy }\end{array}$ & - & $1(5.26)$ \\
\hline
\end{tabular}

Berdasarkan kriteria eksklusi yang ditetapkan sampel dari masing-masing departemen bedah yang diambil berjumlah 19 data pasien untuk bedah hernia dan 60 data pasien untuk bedah SC. Sebanyak 27 (45\%) dari pasien rawat inap dengan prosedur bedah SC berada di rawat inap selama 4 hari dan $1(1.67 \%)$ pasien dengan rawat inap selama 7 hari, untuk bedah hernia pasien berada di rawat inap paling banyak selama 2 dan 4 hari (31.58\%) dan hanya sejumlah 1 orang dengan rawat inap 8 hari $(5.26 \%)$. Prosedur bedah pada pasien SC sebanyak $42(70 \%)$ adalah bedah SC dan sebanyak 10 pasien (52.63\%) pasien HILL menjalani prosedur bedah hernioraphy dengan pemasangan MESH.

Antibiotik pada perawatan bedah umum digunakan terutama pada prosedur bedah yang memiliki risiko infeksi tinggi. Antibiotik pada pasien bedah dapat digunakan sebagai profilaksis dan terapi. Berikut antibiotik yang digunakan pada bedah SC dan hernia pada September - November 2018. 


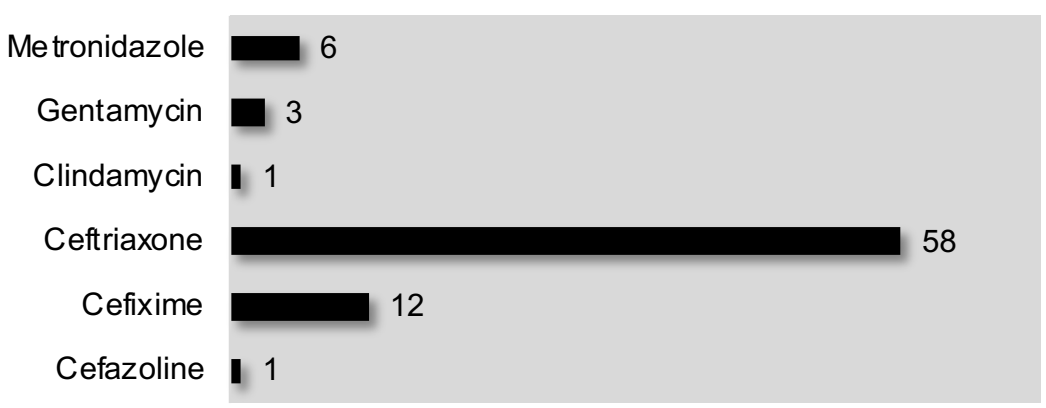

Gambar 1. Penggunaan antibiotik pasien rawat inap bedah SC periode September November 2018 (Total antibiotik yang digunakan $=81$ )

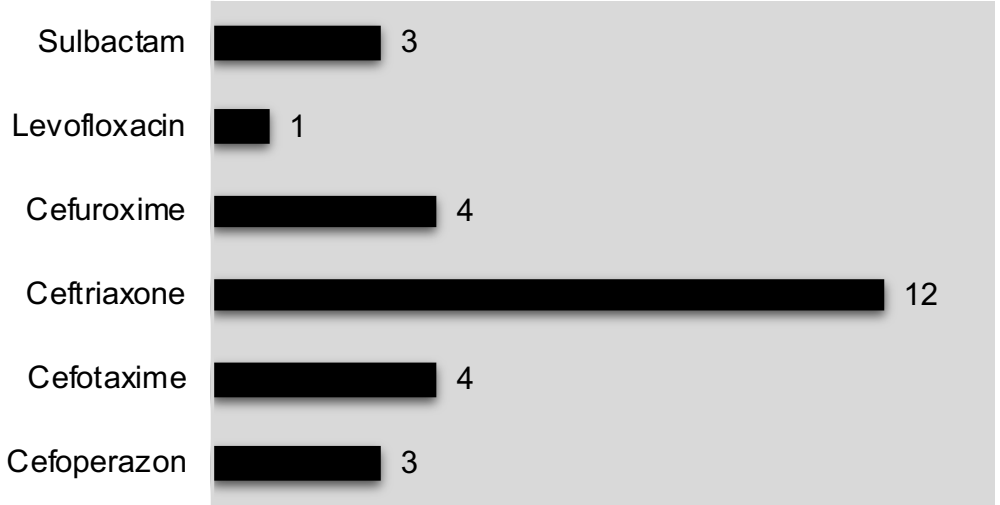

Gambar 2 Penggunaan antibiotik pasien rawat inap bedah hernia periode September - November 2018 (Total antibiotik yang digunakan = 27)

Berdasarkan Gambar 1 dan 2 diketahui bahwa antibiotik yang digunakan oleh pasien rawat inap bedah SC berjumlah total 1 antibiotik dengan 58 (71.6\%) adalah ceftriaxone. Antibiotik ceftriaxone juga menjadi antibiotik yang paling banyak digunakan pada bedah hernia yakni sebanyak 12 antibiotik (44.4\%).

Antibiotik profilaksis adalah antibiotik yang digunakan sebelum prosedur operasi untuk mencegah infeksi luka operasi sedangkan antibiotik terapi merupakan antibiotik yang digunakan pada penyakit infeksi yang dibedakan menjadi terapi empiris (mikroorganisme penginfeksi belum diketahui) dan definitif (mikroorganisme penginfeksi sudah diketahui berdasarkan hasil kultur). Namun tidak setiap prosedur operasi pasien menerima antibiotik profilaksis hanya pada tipe operasi tertentu dengan risiko kontaminasi besar yang diberikan antibiotik profilaksis. Antibiotik terapi diberikan pada kasus terjadinya infeksi luka operasi.

Penggunaan antibiotik harus dikendalikan karena penggunaan yang berlebihan dan tidak tepat data memicu resistensi antibiotik. Untuk menilai penggunaan antibiotik masih berada dalam tingkat wajar dilakukan evaluasi penggunaan antibiotik. 
Tabel 2. Evaluasi Kuantitatif Penggunaan Antibiotik pada Pasien Rawat Inap Bedah SC Periode September - November 2018

\begin{tabular}{|l|l|r|r|r|r|}
\hline \multicolumn{1}{|c|}{ Antibiotik } & Kode & Total DDD & Total DDD/LOS x 100 & \multicolumn{1}{|c|}{$\%$} \\
\hline Ceftriaxone & J01DD04 & 99.5 & 62.58 & 66.78 \\
\hline Cefixime & J01DD08 & 34 & 21.38 & 22.82 \\
\hline Metronidazole & J01XD01 & 12 & 7.55 & 8.05 \\
\hline Clindamycin & J01FF01 & 1.5 & 0.94 & 1.01 \\
\hline Gentamycin & JO1GB03 & 1.333 & 0.84 & 0.89 \\
\hline Cefazoline & J01DB04 & 0.667 & 0.42 & 0.45 \\
\hline
\end{tabular}

Berdasarkan Tabel 2 diketahui bahwa pada setiap 100 pasien di rawat inap bedah SC terdapat 94 pasien menerima 1 DDD antibiotik. Antibiotik yang paling banyak digunakan adalah Ceftriaxone dengan total $62.58 \mathrm{DDD} / 100$ hari rawat, sedangkan yang paling sedikit digunakan adalah Cefazoline yakni 0.45 DDD/100 hari rawat.

Tabel 3. Evaluasi Kuantitatif Penggunaan Antibiotik pada Pasien Rawat Inap Bedah Hernia Periode September - November 2018

\begin{tabular}{|l|l|r|r|r|r|}
\hline \multicolumn{1}{|c|}{ Antibiotik } & Kode & Total DDD & Total DDD/LOS x 100 & \multicolumn{1}{c|}{$\%$} \\
\hline Ceftriaxone & J01DD04 & 21.75 & 32.95 & 65.78 \\
\hline Sulbactam & J01CG01 & 4 & 6.06 & 12.10 \\
\hline Cefuroxime & J01DC02P & 2.667 & 4.04 & 8.07 \\
\hline Cefotaxime & J01DD01 & 2.15 & 3.26 & 6.50 \\
\hline Levofloxacin & J01MA12 & 1.5 & 2.27 & 4.54 \\
\hline Cefoperazon & J01DD12 & 1 & 1.52 & 3.02 \\
\hline & Total & & 50.10 & 100.00 \\
\hline
\end{tabular}

Berdasarkan Tabel 4.3 diketahui bahwa pada setiap 100 pasien di rawat inap bedah hernia terdapat 50 pasien menerima 1 DDD antibiotik. Antibiotik yang paling banyak digunakan adalah Ceftriaxone dengan total $32.95 \mathrm{DDD} / 100$ hari rawat, sedangkan yang paling sedikit digunakan adalah Cefoperazone yakni $1.52 \mathrm{DDD} / 100$ hari rawat.

Hasil evaluasi ini serupa dengan yang dilakukan oleh AMRIN pada tahun 2005 yang menunjukan antibiotik paling banyak diresepkan di bangsal bedah secara umum adalah ceftriaxone dengan 16.4 DDD/100 hari (AMRIN, 2005). Semakin kecil jumlah antibiotik yang digunakan menunjukan dokter lebih selektif dalam meresepkan antibiotik.

\section{Kesimpulan}

Hasil evaluasi kuantitatif penggunaan antibiotik pada pasien rawat ianp bedah SC dan periode bulan September hingga November 2018 menunjukkan antibiotik yang paling banyak digunakan adalah ceftriaxone dengan berturut $32.95 \mathrm{DDD} / 100$ hari rawat untuk bedah hernia dan $62.58 \mathrm{DDD} / 100$ hari rawat untuk bedah SC. 


\section{Daftar Pustaka}

AMRIN. 2005. Penggunaan Antibiotik di RS dr. Soetomo Surabaya dan RSUP dr. Kariadi Semarang. AMRIN Study Group

Central Disease Control and Prevention. 2013. Antibiotic resistance threats in the United States Available at: http://www.cdc.gov/drugresistance/threat-report-2013. Accessed February 132019.

Central Disease Control and Prevention. 2017. Antibiotic Prescribing and Use in the US. Available at http://www.cdc.gov/antibiotic-use/stewardship-report/index.httml. Accessed February 232019.

Cusini A, Herren D, Butikofer L, Pluss-Suard C, Kronenberg A, Marschall J. 2018. Intrahospital differences in anibiotic use correlate with antimicrobial resistance rate in Eschericia coli and Klebsiella penumoniae: a retrospective observational study. Antimicrob Resist Infct Control. 7:89

Grace, Pierce A and Neil R, Borley. 2007. At a Glance Ilmu Bedah. Edisi Ketiga. Jakarta: Erlangga.

Hedrick TL, Smith PW, Gazoni LM, and Sawyer RG. 2007. The Appropriate Use of Antibiotics in Surgery: A Review of Surgical Infections. Curr Probl Surg. 44:635-675

Moore, D. 2016. Antibiotic Classification \& Mechanism. Online available at http://www.orthobullets.com/basic-science/9059/antibiotic-classification-andmechanism. Accessed February 162019.

Nankervis H, Thomas KS, Delamare FM et al. 2016. Scoping systematic review of treatments for eczema. UK: NHR Journals library

Nouwen, J. 2006. Controlling Antibiotic Use and Resistance. Clinical Infectious Disease (Editorial Commentary). 2006:42.

SIGN. 2014. Antibiotic prophylaxis in surgery: A national clinical guideline. Edinburgh: Scottish Intercollgiate Guidelines Network.

Spellberg B and Gilbert DN. 2014. The future of antibiotics and resistance: a tribute to a career of leadership by John Bartlett. Clin Infect Dis. 59: S71-S75.

Ventola, Lee. 2015. The Antibiotic Resistance Crisis. Pharmacy and Therapeutics. 40(4): $277-283$ 
WHO. 2018. WHO Collaborating Centre for Drug Statistics Methodology: Use of ATC/DDD. Online available at http://www.whocc.no/use_of_atc_ddd/ (Accessed February 13 2019).

WHO. 2018. Global Guidelines For The Prevention of Surgical Site Infection. Geneva: World Health Organization. 